Western University Scholarship@Western

Research Program. Impact of the Public Sector on

Research Program. Impact of the Public Sector on

Local Economies Discussion Papers

Local Economies

1975

\title{
Cost-Benefit Analysis and the Use of Urban Land for Transportation
}

Arthur J. Robson

Follow this and additional works at: https://ir.lib.uwo.ca/economicsipsle_dp

Part of the Economics Commons

Citation of this paper:

Robson, Arthur J.. "Cost-Benefit Analysis and the Use of Urban Land for Transportation." Research Program. Impact of the Public Sector on Local Economies Discussion Papers, 006. London, ON: Department of Economics, University of Western Ontario (1975). 


\section{Discussion Paper 006}

COST-BENEFIT ANALYSIS AND THE USE OF URBAN LAND FOR TRANSPORTATION

Arthur J. Robson

\section{RESEARCH PROGRAM: \\ IMPACT OF THE PUBLIC SECTOR ON LOCAL ECONOMIES}

Department of Economics
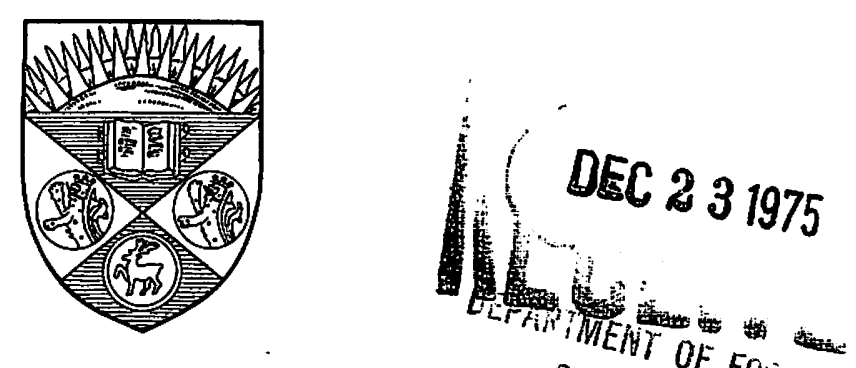

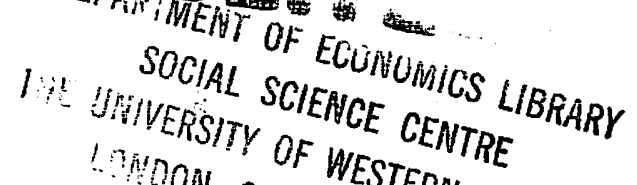$$
\text { ITOON, ONT WESTERN ONTAR }
$$

The University of Western-Ontario

Canada 


\section{Discussion Paper 006 \\ COST-BENEFIT ANALYSIS AND THE USE OF \\ URBAN LAND FOR TRANSPORTATION}

Arthur J. Robson

December, 1975 


\title{
COST-BENEFIT ANALYSIS AND THE USE OF \\ URBAN LAND FOR TRANSPORTATION
}

\author{
Arthur J. Robson \\ Department of Economics \\ University of Western Ontario \\ London, Ontario, Canada
}

\begin{abstract}
This paper investigates the allocation of resources, particularly 7 and, within a suburban city where transportation is subject to congestion. In the competitive case, the allocation of land is decided (erroneously) by cost-benefit analysis. This is, perhaps, the best model of the real world process, at this level of abstraction. It is found that the road then built is wider everywhere than the road in the fully optimum case. Hence, if taxes and regulations will eventually be imposed to reduce the gap between the social and private cost of commuting, possibly too much 7 and is already used for roads in American cities.
\end{abstract}




\section{COST-BENEFIT ANALYSIS AND THE USE OF \\ URBAN LAND FOR TRANSPORTATION *}

Arthur J. Robson

\section{Introduction}

The competitive and optimal allocation of resources, including 1 and, within an urban area where transportation involves congestion has been studied by a number of theorists. (See Solow [8], for an example of the competitive case, and Dixit [1], for one of the optimum case.) My intention here is to study the relationship between the competitive case, where the allocation of 1 and is decided by the application of cost-benefit analysis, and the fully optimum case. The fact that cost-benefit analysis may lead to erroneous use of land was shown originally by Solow and Vickrey [9], in the context of a model of firm location where there was no elasticity of demand for 1 and. The nature of the two cases studied here is similar to those compared by Legey, Ripper and Varaiya [3], but, al though they allow capital to be used in the production of housing and transportation services, they then assume that there is no elasticity of demand for housing. Kanemoto [2], also, studies the relationship between the competitive, costbenefit, case and the optimum. However, as he is aware (see section 5 of his paper), the model which he uses of industrial use of the land does not fully incorporate the features of residential use of land. Kanemoto uses a linearproduction function with space as the sole input. When he allows gross output to be determined within the model, the total amount of traffic in the competitive case is not the same as in the optimum. For a residential model, this would seem to correspond to changing the total population of the 
town. This makes it difficult to see a direct analogy here. He then considers a fixed total gross output, and the results are, in fact, similar to those derived in this paper. The total amount of land used is now fixed, and his model is a circular version of the original Solow and Vickrey [8] model, with certain simplifications to make analytic solutions possible. My paper is then designed to address the same questions as Kanemoto [2], with explicit residential use of the 1 and. Residents perform more meaningful optimization, and the rental function arises as the ratio of marginal utilities in the usual way.

The model I will use is essentially that of Solow [8], and Dixit [1]. I will limit myself to a particular choice of two of the parameters. Although the general case is soluble, it is difficult to compare the solution in the two regimes. In the optimum case, I will consider just the case where utilities are constrained to be equal. This facilitates comparison with the competitive case where everyone has the same income. After the theoretical results are presented, a numerical example is given. This is not, unfortunately, superfluous due to the implicit way in which the constants of integration are related in the two regimes.

\section{Competition}

Reference might be made to Solow [8], for a discussion of the model outlined below. We have a radially symmetric suburban city, with radius $R$, and where the CBD is assigned radius 1 . Everyone has a fixed trip requirement to the $C B D$, and has the same utility function

$$
u(s, z)=s \cdot z
$$

where $z$ is the consumption good, and $s$ is space. (The problem is soluble 
for more general Cobb-Douglas utility functions.)

The budget constraint is

$$
y=z+r(x) s+t(x)
$$

where $y$ is the common level of income, $r(x)$ is the rent at radial distance $x$, and $t(x)$ is the cost of commuting from $x$ to the edge of the CBD. It can be shown that, for consumer equilibrium,

$$
\begin{aligned}
& r(x) s=z=\frac{1}{2} y w(x) \\
& r(x)=r(1) w(x)^{2}
\end{aligned}
$$

where we define

$$
w(x)=(y-t(x)) / y
$$

We have the following equality between 1 and demanded and supplied at each radial distance $x$

$$
n(x) s=2 \pi x b(x)
$$

where $n(x) d x$ is the number of people living between $x$ and $x+d x$, and $b(x)$ is the fraction of arc devoted to residences at $x$. We define

$$
N(x)=\int_{x}^{R} n(x) d x
$$

Then we can show that

$$
N^{\prime}(x)=-\frac{4 \pi r(1)}{y} x b(x) w(x)
$$

The cost of transportation, $t(x)$, incorporates congestion as follows 


\section{$-4-$}

$$
t(x)=a \int_{1}^{x} \frac{N(x)}{2 \pi x(7-b(x))} d x
$$

The problem where the integrand is raised to power $\mathrm{m}$, say, is once again soluble but is not considered here. Hence we have that, in this case,

$$
w^{\prime}(x)=-\frac{a}{y}\left\{\frac{N(x)}{2 \pi x(1-b(x))}\right\}
$$

Equations (8) and (10) now provide the solution for the problem if the function $b(x)$ is assumed to be given. We have three boundary conditions

$$
N(1)=N \quad N(R)=0 \quad W(1)=1
$$

where $N$ is the total population of the city. We need the extra condition to determine $r(1)$, which can be shown to be related to the common level of utility, $u^{\mathrm{C}}$ say, as follows

$$
r(1)=y^{2} /\left(4 u^{c}\right)
$$

Up to this point the analys is is due to Solow [8]. At this point, he assumed that the fraction of arc devoted to roads was constant; the two assumptions mentioned here were then necessary in order to derive a closed form solution. In terms of the actual structure of cities, it seems to me, the best assumption is that the appropriate authorities actually use a less sophisticated version of the following cost-benefit approach.

\section{(a) Cost-Benefit Analysis}

Suppose that the allocation of land between residential uses and transportation is decided as follows. The road is widened to the point at which the marginal benefit from further widening in terms of the reduced total cost of transportation equals the marginal cost for the 1 and 
converted from residential use, valued at the market rental value. This is not the true second-best solution, since the market does not value land appropriately in the presence of congestion. Suppose that we consider allocating an extra fraction of arc $d b$ to the road over a radial distance $d x$, at the point $x$. Then, in fact, the apparent net benefit is a global maximum if

$$
a \frac{N(x)^{2}}{2 \pi x(7-b(x))^{2}} d b d x=2 \pi x r(x) d b d x
$$

From equations (4) and (10), we get that

$$
w^{\prime}(x)=-(j / 2) \cdot w(x)
$$

where we define

$$
j=2\left\{\frac{\operatorname{ar}(1)}{y^{2}}\right\}^{\frac{1}{2}}=\left\{\frac{a}{u^{c}}\right\}^{\frac{1}{2}}
$$

using equation (12). The solution of equation (14), since $w(1)=1$, is clearly

$$
w(x)=\exp -j(x-1) / 2
$$

From equations (8), (10) and (16) we can derive a differential equation for $v(x)=x(1-b(x))$. It is

$$
v^{\prime}(x)=-j(x-(3 / 2) v(x))
$$

The boundary condition for $v(x)$ is $v(R)=0$. (Consider equation (10) in the light of the solution for $w(x)$, equation (16).) We can show that $(1-b(x))^{\prime}<0$, that is, that the fraction of arc devoted to the road 
declines with increasing radial distance. Suppose that it does not, then there must exist some $x^{\star}$, at which $(1-b(x))$ is a maximum, because $(1-b(x))^{\prime}$ is certainly negative at $x=R$. Then we have that

$$
\left.(1-b(x))^{\prime}\right|_{x=x^{*}}=0
$$

Then, from equation (17) and the definition of $v(x)$, we have that

$$
v^{\prime}\left(x^{*}\right)=\left(1-b\left(x^{*}\right)\right)=-j x^{*} \cdot\left(1-(3 / 2) \cdot\left(1-b\left(x^{*}\right)\right)\right)
$$

and since $b\left(x^{*}\right)$ must clearly be less than one, it must be that the righthand side of equation (19) is positive. However, by differentiation of equation (17), we have

$$
v^{\prime \prime}\left(x^{*}\right)=\left.x(1-b(x)) "\right|_{x=x^{*}}=-j\left(1-(3 / 2) \cdot\left(1-b\left(x^{*}\right)\right)\right)
$$

Since $x^{*}$ is positive, we then have that $(1-b(x))^{\prime \prime}$ is positive at $x=x^{*}$, contradicting the assumption that a maximum exists. Hence we have

$$
(1-b(x))^{\prime}<0
$$

for all $x$. The solution of $(17)$, given that $v(R)=0$, can be shown to be

$$
v^{C}(x)=(2 x / 3+4 /(9 j))-(2 R / 3+4 /(9 j)) \exp -3 j(r-x) / 2
$$

In the above equation, and in other equations to follow which will be compared with the results in the optimum case, the suffix ' $c$ ' is used to denote the competitive case. The solution for $N(x)$ is then from equation (10),

$$
N^{C}(x)=\frac{\pi y j}{a} v^{C}(x) w(x)
$$


where $w(x)$ is given by $(16)$. The boundary condition that $N(1)=N$ then fixes the value of $j$ and hence that of $r(1)$ and of $u^{c}$. It can be shown easily that the right-hand side of $(23)$, when $x=1$, is monotonic in $j$, vanishes at $j=0$, and tends to infinity as $j$ tends to infinity. Hence a unique solution always exists. The rental profile is now, from equations (4) and (16),

$$
r^{c}(x)=r(1) \exp -j(x-1)
$$

The distribution of the consumption good, from (3) and (16), is

$$
z^{C}(x)=\frac{1}{2} y \exp -j(x-1) / 2
$$

The distribution of space, from (3) and (24), is given by

$$
s^{c}(x)=y /(2 r(1)) \cdot \exp j(x-1) / 2
$$

It may be shown, from $(15),(23)$ and (24), that the traffic density

$$
\rho^{C}(x)=N^{C}(x) / v^{C}(x)
$$

is related to the rental profile as follows

$$
\rho^{c}(x)=\left\{\frac{4 \pi^{2}}{a} r^{c}(x) \cdot\right\}^{\frac{3}{2}}
$$

In order to compare this competitive case with the optimum of the next section, we should assume that the total amount spent on transportation and on the consumption good is the same in both cases. If this total amount is denoted by $Y$, then clearly we have that

$$
Y=N y-P
$$

where $P$ is the total bill for residential land rental. We have 


$$
\begin{gathered}
P=\int_{1}^{R} n(x) \operatorname{sr}(x) d x=2 \pi r(1) \int_{1}^{R}(x-v(x)) w(x)^{2} d x \\
=\frac{\pi y^{2}}{18 a} \cdot\{(3 j-1)-(3 R j-1) \exp -(r-1) j+4(3 R j+2) \\
\cdot[\exp -(R-1) j-\exp -3(R-1) j / 2]\}
\end{gathered}
$$

as follows from (16) and (22) after manipulation. Also, however, the total amount of resources, $Y$, can be expressed as ${ }^{1}$

$$
\begin{aligned}
Y & =\int_{1}^{R}\left\{n(x) z(x)+\frac{N(x)^{2}}{2 \pi x(1-b(x))}\right\} d x \\
& =\int_{1}^{R}\left\{\frac{2 \pi x b(x) z(x)}{s}+2 \pi x(1-b(x)) r(x)\right\} d x \\
& =\int_{1}^{R} 2 \pi x r^{C}(x) d x
\end{aligned}
$$

using (6), (13) and (3). Hence $Y$ is the total value of 1 and in the city, whether used for the road or for residential uses.

It seems to me that Dixit [1], should have used this competitive, cost-benefit case to explain the structure of real cities. It certainiy is not true that congestion is fully accounted for in the real world, as his model assumed.

\section{Optimum}

We will now consider the optimum case under the same technological conditions as in the last section. In the present situation, we will suppose that everyone has the same level of utility. This then is 
essentially the Rawlsian case. We will formulate the problem in terms of the Maximum Principle with parameters. (See Pontryagin et at. [6], pp. 191-197.) Oron et a1. [5], use a calculus of variations approach to solve a similar approach.

We seek then to minimize $1 / u^{*}$, the reciprocal of the common level of utility. We have that

$$
u^{*}=2 \pi x b(x) z(x) / n(x)
$$

using equations (1) and (6). We will use this equation to eliminate $n(x)$ throughout the problem. We have the constraint that

$$
N^{\prime}(x)=-n(x)=-2 \pi x b(x) z(x) / u^{*}
$$

Also we define

$$
Y^{\prime}(x)=\frac{2 \pi x b(x) z(x)^{2}}{u^{*}}+a \frac{N(x)^{2}}{2 \pi x(1-b(x))}
$$

as the rate of use of resources on consumption and transportation. We then take

$$
Y(1)=0 \quad Y(R)=Y
$$

where $Y$ is, as in the last section, the total amount of income available to be used for transportation or for the consumption good. The Hamiltonian for minimizing $1 / u^{*}$ subject to the two different equation constraints, (33) and (34), can be written as follows

$$
\begin{aligned}
\mathcal{F}=\psi_{0} \cdot\left(u^{*}(R-1)\right)^{-1} & +\psi_{1} \cdot\left\{\frac{2 \pi x b(x) z(x)^{2}}{u^{*}}+\frac{a N(x)^{2}}{2 \pi x(1-b(x))}\right\} \\
& -\psi_{2}(x) \cdot \frac{2 \pi x b(x) z(x)}{u^{*}}
\end{aligned}
$$


where the $\psi_{i}$ are the costate variables. The remaining control variables are $b(x)$ and $z(x)$. Suppose that these controls are interior, that is, that $z(x) \varepsilon(0, \infty)$ and $b(x) \varepsilon(0,1)$. Then we have that

$$
\begin{aligned}
& \frac{\partial \mathcal{H}}{\partial z}=0 \text { and hence } 2 \psi_{1} z(x)=\psi_{2}(x) \\
& \frac{\partial \mathcal{H}}{\partial b}=0 \text { and hence } \frac{z(x)^{2}}{u^{*}}=a\left\{\frac{N(x)}{2 \pi x(7-b(x))}\right\}^{2}
\end{aligned}
$$

Since $Y(x)$ does not appear in the Hamiltonian, $\psi_{1}$ is, as written, constant. The adjoint equation for $\psi(x)$ is

$$
\psi_{2}^{\prime}(x)=-\frac{\partial \partial f}{\partial N}=-\frac{a N(x)}{\pi x(1-b(x))} \cdot \psi_{1}
$$

From equations (37), (38) and (39), we can establish that

$$
z^{\prime}(x) / z(x)=-\left(a / u^{*}\right)=-k
$$

say. We will use the suffix "*" to refer to this optimum case, for purposes of comparison with the competitive case. Hence we have that

$$
z^{*}(x)=z(1) \exp -k(x-1)
$$

Also from equations (33), (38) and (41), we can show that

$$
v^{\prime}(x)=-k(x-2 v(x))
$$

where $v(x)=x(1-b(x))$. From equations (38) and (41), and since $N(R)=0$, we must have that $v(R)=0$. Then the solution of (42) is

$$
v^{*}(x)=\left(\frac{1}{2} x+1 /(4 k)\right)-\left(\frac{1}{2} R+1 /(4 k)\right) \exp 2 k(x-R)
$$


It can be established from equation (42) that $(1-b(x))^{\prime}<0$, in a similar way to the last section. We can in fact show that, by integrating equation (34) using (41) and (43), that

$$
z(1)=Y / N
$$

The solution for $N(x)$ is then, from equation (38),

$$
N^{*}(x)=\frac{2 \pi k}{a} \cdot v^{*}(x) z^{*}(x)
$$

The condition that $N(1)=N$ determines the value of $k$. This value can readily be shown to exist and to be unique. Although no rent is actually paid in this optimum case, the shadow price of 1 and is given by

$$
r^{*}(x)=\frac{u_{s}(x)}{u_{z}(x)}=\frac{z(x)}{s(x)}=\frac{z(1)^{2}}{u^{*}} \cdot \exp -2 k(x-1)
$$

since the distribution of space is given by

$$
s^{*}(x)=u * / z^{*}(x)=u^{*} /(z(1)) \cdot \exp k(x-1)
$$

We can show that the traffic density

$$
\rho *(x)=N^{*}(x) / v^{*}(x)
$$

is related to the rental profile as follows

$$
\rho^{*}(x)=\left\{\frac{4 \pi^{2}}{a} \cdot r^{*}(x)\right\}^{2}
$$

using equations (38), (41) and (46). Also it can be established, by a similar method to that used in the last section, that

$$
y=\int_{1}^{R} 2 \pi x r^{*}(x) d x
$$


Thus $Y$, the total amount of resources as in the last section, is again the total value of all land in the city. To decentralize this optimum case, it can be shown that commuters should be charged rent for the 1 and which they use for transportation, as in Riley [7]. Then the level of income, $y^{*}$, which should be given each person is, in fact,

$$
y^{*}=2 Y / N
$$

It may be established that the solution to this optimum problem exists if we restrict the value of $z(x)$ so that the control set is compact. (See McShane [3].) We can rule out $\psi_{1}=0$, by contradiction. The solution must therefore have an interior portion. In fact, for large enough bound on $z(x)$, it can be shown to be always interior. Hence the solution described is the unique solution.

\section{Comparison of the Two Regimes}

If the optimum city has the same size as the competitive city, the forms of equations (17) and (42) are enough to establish that the costbenefit road is everywhere larger than the optimum road. For we have that $j>k$, since $u^{*}>u^{c}$, if the same amount of income $Y$ is available in each case.

Let us call the solutions of equations (17) and (42) $v^{C}(x)$ and $v *(x)$ respectively, as before. It will be convenient to consider the solution $v^{i}(x)$ of the following equation

$$
v^{i_{1}}(x)=-k\left(x-(3 / 2) v^{i}(x)\right) \text { with } v^{i}(R)=0
$$

First compare $v^{*}(x)$ and $v^{i}(x)$. We have that $v^{i}(R)=v^{*^{\prime}}(R)$, but we can show that 


$$
v^{*} "(R)<v^{i^{\prime \prime}}(R)<0
$$

which shows that $v^{\star}(x)$ is narrower than $v^{j}(x)$ in some neighbourhood of $x=R$. Suppose that these two profiles again intersect at $x=x^{*}$, say. Then we can show that

$$
v^{* 1}\left(x^{*}\right)-v^{i}\left(x^{*}\right)=\frac{3}{2} k v_{0}\left(x^{*}\right)>0
$$

which is a contradiction. Hence $v^{*}(x)$ is always narrower than $v^{i}(x)$. Let us now define

$$
d(x)=v^{c}(x)-v^{i}(x)
$$

We will show that $d(x)$ is always positive. We can easily show that

$$
d^{\prime}(x)=-(j-k) \cdot(x-(3 / 2) d(x)) \text { with } d(R)=0
$$

Hence this function has only maxima, as may be checked by differentiation of equation (56) when $d^{\prime}(x)=0$. At any point where $d(x)=0$, we have that $d^{\prime}(x) \leqslant 0$, since $x=0$. It is clear that $d(x)$ is positive in a neighbourhood of $x=R$, from (56), hence it must always be positive. Hence $v^{i}(x)$ is always narrower than $v^{c}(x)$. Altogether then, we have proved that $v^{*}(x)$, the solution in the optimum case, is always narrower than $v^{c}(x)$, the solution in the competitive case based on cost-benefit analysis. This conclusion can be seen to hold also for the case where the optimum city is smaller than the competitive case, a fortiori. The total value of land in the two regimes is the same, from equations (37) and (50). Hence the rental functions must intersect at least once. In fact, considering additionally the form of these two functions, equations (24) and (46), they must be either identical or intersect exactly once. From equations (28) 
and (49), the same conclusion holds for the traffic density profiles. In fact, unless $u^{*}>4 u^{c}$, the optimal rent function is steeper at the intersection than is the competitive rent function. Hence congestion is higher in the optimal town near the CBD, but lower at the boundary. This conclusion was also obtained by Kanemoto [2], when he assumed that the gross output in his model was to be fixed. If the optimum rent function is steeper at the intersection than the competitive rent profile, the rent at any fixed boundary will be lower in the optimum case than in the competitive case. Hence the optimum city will be smaller than the competitive city for any given boundary rent condition. The condition that $u^{*}<4 u^{C}$ wi11 be met if the amount used for transportation is a sufficiently small fraction of the total amount of resources. It would certainly seem to be the usual case.

\section{A Numerical Example}

Suppose that we have a city of 100,000 persons each with income $\$ 10,000$. The parameter $a$ is 0.02 . The radius of the city is 5 miles. These values were used by Solow [8], so they form the basis of a comparison.

(a) Competition

From equation (23) we must find the value of $j$ satisfying

$$
\frac{2 \pi y}{9 a N} \cdot((3 j+2)-(3 R j+2) \exp 3(1-R) / 2)=1
$$

With the above figures we find

$$
\begin{aligned}
j & =0.08467 / \mathrm{mile} \\
u^{\prime} & =2.790 \$ . \mathrm{mile}^{2}
\end{aligned}
$$

using equation (15). The values of $r(x), s(x), z(x), v(x)$, and $n(x)$ at 
$x=1$ and at $x=5$ are given in Table $I .^{2}$ The total amount spent on rent, $P$, is given by equation (30). In this case

$$
P=4.363 \times 10^{8} \$
$$

which is, as it should be, somewhat less than half the total income of $10^{9} \$$.

(b) Optimum with Boundary Rent Condition

Suppose that the opportunity cost of land is, in fact, the value actually attained in the competitive case at $R=5$. Hence we have, where $r_{a}$ is the opportunity cost of 1 and

$$
r_{\mathrm{a}}=6.387 \times 10^{6} \$ / \mathrm{mile} \mathrm{e}^{2}
$$

The optimum city will here, as will be shown, be smaller than the competitive city. Hence we must allow for the extra income arising from not occupying some 1 and. For instance, it might be imagined that farmers pay rent on the 1 and to the city's residents. We will have

$$
z(1)=\left.z(1)\right|_{R=5}+r_{a} \cdot \pi\left(25-R^{2}\right) / N
$$

where

$$
\left.z(1)\right|_{R=5}=y-P / N=5.637 \times 10^{3} \$
$$

The value of $k$ satisfies equation (45) at $x=1$; hence we have that

$$
\frac{\pi z(1)}{2 a N} \cdot((2 k+1)-(2 R k+1) \exp -2 k(R-1))=1
$$

Finally we have the rental condition, from equation (46), 


$$
r_{a}=\frac{z(1)^{2} \cdot k^{2}}{a} \cdot \exp -2 k(R-1)
$$

We then need to find $z(1), k$, and $R$ to satisfy equations (58), (59) and (60) simultaneously. Iteration yields

$$
\begin{aligned}
k & =0.08329 / \mathrm{mile} \\
u^{*} & =2.883 \$ . \mathrm{mile}^{2} \\
R & =4.858 \mathrm{miles}
\end{aligned}
$$

The values of $r(x), s(x), z(x), v(x)$, and $n(x)$ are given, at $x=1$ and at $X=R=4.858$, in Table II.

Hence we have, in the optimum case as compared with the competitive case, the following points of difference:

(1) Utility is higher, of course, but not nearly by a factor of four.

(2) The overall radius of the city falls, given the same boundary rent condition.

(3) The rent is much higher at $x=1$, and falls more sharply with $x$.

(4) The amount of space per person is much less at $x=1$, a little more at $x=R$, and the rate of exponential increase is greater.

(5) The amount of consumption good is everywhere greater, but particularly at $x=1$, and the rate of decrease is greater.

(6) The road is everywhere narrower.

(7) The distribution of the population becomes much more concentrated towards the CBD.

This numerical example demonstrates some of the complexity of the full general equilibrium comparison. 
TABLE 1. The Competitive Case

\begin{tabular}{llll}
\hline Variable & \multicolumn{1}{c}{ Value at $x=1$} & Value at $x=R=5$ & Equation \\
\hline$r(x)$ & $8.962 \times 10^{6} \$ / \mathrm{mi}^{2}$ & $6.387 \times 10^{6} \$ / \mathrm{mi}^{2}$ & $(24)$ \\
$s(x)$ & $5.579 \times 10^{-4} \mathrm{mi}^{2} /$ person & $6.608 \times 10^{-4} \mathrm{mi}^{2} /$ person & $(26)$ \\
$z(x)$ & $5.000 \times 10^{3} \$ /$ person & $4.221 \times 10^{3} \$ /$ person & $(25)$ \\
$v(x)$ & $0.7519 \mathrm{mi}$ & $0.0000 \mathrm{mi}$ & $(22)$ \\
$n(x)$ & $2.795 \times 10^{3}$ person $/ \mathrm{mi}$ & $4.754 \times 10^{4}$ person $/ \mathrm{mi}$ & $(6)$ \\
\hline
\end{tabular}

TABLE 2. The Optimum Case

\begin{tabular}{llll}
\hline Variable & \multicolumn{1}{c}{ Value at $x=1$} & Value at $x=R=4.858$ & Equation \\
\hline$r(x)$ & $1.215 \times 10^{7} \$ / \mathrm{mi}^{2}$ & $6.387 \times 10^{6} \$ / \mathrm{mi}^{2}$ & $(46)$ \\
$s(x)$ & $4.872 \times 10^{-4} \mathrm{mi}^{2} /$ person & $6.717 \times 10^{-4} \mathrm{mi}^{2} /$ person & $(47)$ \\
$z(x)$ & $5.918 \times 10^{3} \$ /$ person & $4.292 \times 10^{3} \$ /$ person & $(41)$ \\
$v(x)$ & $0.5128 \mathrm{mi}$ & $0.0000 \mathrm{mi}$ & \\
$n(x)$ & $6.283 \times 10^{3}$ person $/ \mathrm{mi}$ & $4.544 \times 10^{4}$ person $/ \mathrm{mi}$ & \\
\hline
\end{tabular}




\section{Conclusions}

It would appear likely that the present system of applying costbenefit analysis, albeit less sophisticated than here, will lead to too many roads being provided, as compared with the case where the full congestion cost is somehow levied on commuters. It would seem that to get away from the particular assumptions on utility functions and the congestion cost function, a more fully numerical approach will be needed. If one despairs of ever imposing an approximately correct congestion tax, the most relevant case with which to compare the cost benefit case would be the competitive case where the road is selected to be the true second-best solution. Unfortunately, the assumption that rent be redistributed, which is more reasonable than an "absentee landlord" assumption is then a major analytic stumbling-block. I have solved the second-best case where rent are lost to absentee landlords, for a limited set of the parameters, but I am not sure as to the relevance of this case. 


\section{FOOTNOTES}

*This paper is forthcoming in the Journal of Urban Economics. To some extent, it draws on my Ph.D. thesis submitted to the Department of Economics, M.I.T., in May 1974. I would like to thank without implicating the members of my thesis committee--Professors R. M. Solow, M. L. Weitzman, and $W$. C. Wheaton. A referee also made detailed suggestions for which I am grateful.

${ }^{1}$ The referee pointed this out.

${ }^{2}$ The rate of increase in space per person and the rate of decrease in rent seem low; however, one of the most salient features of the real world--the fact that rich people live in the suburbs and the poor people in the centre--is not modelled. 


\section{REFERENCES}

[1] Dixit, A., "The Optimum Factory Town," Bell Journal of Economics and Management Science 4 (1973): 637-651.

[2] Kanemoto, Y., "Congestion and Cost-Benefit Analysis in Cities," Journal of Urban Economics (forthcoming).

[3] Legey, L., Ripper, M., and Varaiya, P., "Effects of Congestion on the Shape of a City," Journal of Economic Theory 6 (1973): 162-179.

[4] McShane, E. J., "Optimal Controls, Relaxed and Ordinary," in A. Bal akrishan and L. Neustadt, eds., Mathematical Theory of Control (Academic Press, New York, 1967).

[5] Oron, Y., Pines, D., and Sheshinski, E., "The Effect of Nuisances Associated with Urban Traffic on Suburbanization and Land Values," Journal of Urban Economics 1 (1974): 382-394.

[6] Pontryagin, L., et al., The Mathematical Theory of Optimal Processes (Interscience, New York, 1962).

[7] Riley, J., "Optimal Residential Density and Road Transportation," Journal of Urban Economics 1 (1974): 230-249.

[8] Solow, R. M., "Congestion, Density and the Use of Land for Transportation," Swedish Journal of Economics 74 (1972): $161-173$.

[9] Solow, R. M., and Vickrey, W. S., "Land Use in a Long Narrow City," Journal of Economic Theory 3 (1971): 430-447. 
RESEARCH PROGRAM:

IMPACT OF THE PUBLIC

SECTOR ON LOCAL ECONOMIES

The Department of Economics, University of Western Ontario, has recently mounted a long-term research program on the Impact of the Public Sector on Local Economies. The program publishes Discussion Papers and Research Studies. Copies may be obtained by writing:

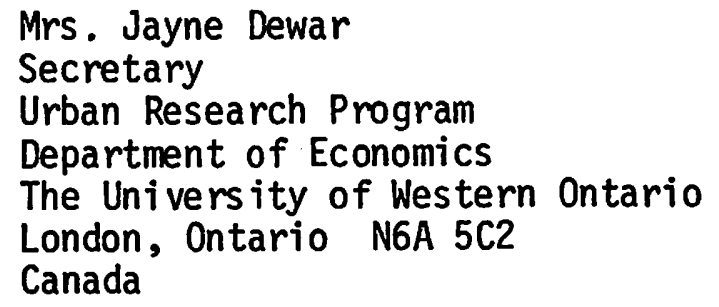

The following Discussion Papers and Research Studies are currently avail able :

DISCUSSION PAPERS:

001 P. T. Chinloy, "Hedonic Prices and Age Deterioration in Urban and Suburban Housing" (September 1975).

002 M. W. Frankena, "Alternative Models of Rent Control" (September 1975).

003 J. R. Markusen. and D. T. Scheffman, "Ownership Concentration and Market Power in Urban Land Markets" (October 1975).

004 A. J. Robson, "The Effect of Urban Structure on Ambient Pollution" (October 1975).

005 J. R. Markusen and D. T. Scheffman, "The Timing of Residential Land Development: A General Equilibrium Approach" (November 1975).

006 A. J. Robson, "Cost-Benefit Analysis and the Use of Urban Land for Transportation" (December 1975). 


\section{RESEARCH STUDIES:}

01 G. W. Davies and P. L. Jackson, "A Model of the Urban Housing and Residential Land Markets" (September 1975).

02 G. P. Schaefer, "The Urban Area Production Function and the Urban Hierarchy: The Case of Saskatchewan" (October 1975). 